\title{
The Human T Cell Receptor Alpha Variable (TRAV) Genes
}

\author{
Dominique Scaviner Marie-Paule Lefranc \\ Laboratoire d'ImmunoGénétique Moléculaire, CNRS, Université Montpellier II, \\ Montpellier, France
}

\section{Key Words}

Human genes · IMGT - T cell receptor -

Alpha variable genes

\begin{abstract}
'Human T Cell Receptor Alpha Variable (TRAV) Genes', the eighth report of the 'IMGT Locus in Focus' section, comprises four tables: (1) 'Number of human germline TRAV genes at 14q11 and potential repertoire'; (2) 'Human germline TRAV genes at 14q11'; (3) 'Human TRAV allele table', and (4) 'Correspondence between the different human TRAV gene nomenclatures'. These tables are available at the IMGT Marie-Paule page of IMGT, the international ImMunoGeneTics database (http://imgt.cines.fr:8104) created by Marie-Paule Lefranc, Université Montpellier II, CNRS, France.
\end{abstract}

Copyright $\odot 2000$ S. Karger AG, Basel

\section{Introduction}

'Human T Cell Receptor Alpha Variable (TRAV) Genes' is the eighth report of the 'IMGT Locus in Focus' section, launched in the April 1998 issue of Experimental and Clinical Immunogenetics [1]. We have previously reported the complete repertoire of the human germline IGH, IGK and IGL genes [2-6], and that of the human germline TRBV genes [7]. This eighth report on the human $\mathrm{T}$ cell receptor alpha variable genes comprises four tables: (1) 'Number of human germline TRAV genes at 14q11 and potential repertoire'; (2) 'Human germline TRAV genes at 14q11'; (3) 'Human TRAV allele table', and (4) 'Correspondence between the different human TRAV gene nomenclatures'. These tables are available at the IMGT MariePaule page of IMGT, the international ImMunoGeneTics database (http://imgt.cines. fr:8104) created by Marie-Paule Lefranc, Université Montpellier II, CNRS, France [8-10]. Descriptions of functionality (functional, open reading frame, pseudogene) and mutations are in accordance with the IMGT Scientific chart [10], available at the IMGT MariePaule page. Nucleotide and amino acid numbering of the V-REGION is in accordance with the unique IMGT numbering system [9, $11,12]$.

\begin{tabular}{ll}
\hline KARGER & ( ) 2000 S. Karger AG, Basel \\
Fax +4161306 1234 & 0254-9670/00/0172-0083\$17.50/0 \\
$\begin{array}{l}\text { E-Mail karger@karger.ch } \\
\text { www.karger.com }\end{array}$ & $\begin{array}{l}\text { Accessible online at: } \\
\text { www.karger.com/journals/eci }\end{array}$
\end{tabular}

Prof. Marie-Paule Lefranc, Université Montpellier II

Lab. d'ImmunoGénétique Moléculaire, LIGM, UPR CNRS 1142, IGH 141, rue de la Cardonille, F-34396 Montpellier Cedex 5 (France)

Tel. +33499619965, Fax +33499619901

E-Mail lefranc@ligm.igh.cnrs.fr, IMGT: http://imgt.cines.fr:8104 
Table 1

Number of human germline TRAV genes at $14 \mathrm{q} 11.2$

and potential repertoire

IMGT TRAV subgroups are according to Boysen, C. et al., unpublished (AE000658 - AE000661).

54 TRAV genes belonging to 41 subgroups, on 700 kilobases :

45 FUNCTIONAL

7 PSEUDOGENE

2 FUNCTIONAL Or PSEUDOGENE

Potential repertoire : 45-47 FUNCTIONAL TRAV genes belonging to 41 subgroups

\begin{tabular}{|c|c|c|c|c|}
\hline Subgroup & Functional & ORF & Pseudogene & Total \\
\hline TRAV1 & 2 & - & - & 2 \\
\hline TRAV2 & 1 & - & $=$ & 1 \\
\hline TRAV3 & $\left(1^{*}\right)$ & - & $\left(1^{*}\right)$ & 1 \\
\hline TRAV4 & 1 & - & - & 1 \\
\hline TRAV5 & 1 & - & - & 1 \\
\hline TRAV6 & 1 & - & - & 1 \\
\hline TRAV7 & 1 & - & - & 1 \\
\hline TRAV8 & 6 & - & 1 & 7 \\
\hline TRAV9 & 2 & - & - & 2 \\
\hline TRAV10 & 1 & - & - & 1 \\
\hline TRAV11 & 1 & - & - & 1 \\
\hline TRAV12 & 3 & - & - & 3 \\
\hline TRAV13 & 2 & - & - & 2 \\
\hline TRAV14/DV4 & 1 & - & - & 1 \\
\hline TRAV15 & - & - & 1 & 1 \\
\hline TRAV16 & 1 & - & - & 1 \\
\hline TRAV17 & 1 & - & - & 1 \\
\hline TRAV18 & 1 & - & - & 1 \\
\hline TRAV19 & 1 & - & - & 1 \\
\hline TRAV20 & 1 & - & - & 1 \\
\hline TRAV21 & 1 & - & - & 1 \\
\hline TRAV22 & 1 & - & - & 1 \\
\hline TRAV23/DV6 & 1 & - & - & 1 \\
\hline TRAV24 & 1 & - & - & 1 \\
\hline TRAV25 & 1 & - & - & 1 \\
\hline TRAV26 & 2 & - & - & 2 \\
\hline TRAV27 & 1 & - & - & 1 \\
\hline TRAV28 & $=$ & - & 1 & 1 \\
\hline TRAV29/DV5 & $(1)^{*}$ & - & $(1)^{*}$ & 1 \\
\hline TRAV30 & 1 & - & - & 1 \\
\hline TRAV31 & - & - & 1 & 1 \\
\hline TRAV 32 & - & - & 1 & 1 \\
\hline TRAV 33 & - & - & 1 & 1 \\
\hline TRAV34 & 1 & - & - & 1 \\
\hline TRAV35 & 1 & - & - & 1 \\
\hline TRAV36/DV7 & 1 & - & - & 1 \\
\hline TRAV37 & - & - & 1 & 1 \\
\hline TRAV38/DV8 & 2 & - & - & 2 \\
\hline TRAV39 & 1 & - & - & 1 \\
\hline TRAV40 & 1 & - & - & 1 \\
\hline TRAV41 & 1 & - & - & 1 \\
\hline Total & $45(+2)^{*}$ & 0 & $7(+2)^{*}$ & 54 \\
\hline
\end{tabular}

* FUnCTIONAL or PSEUdogENE (TRAV3, TRAV29/DV5)

Author: Dominique Scaviner (domi@ligm.igh.cnrs.fr)

Created: $17 / 06 / 99$ 


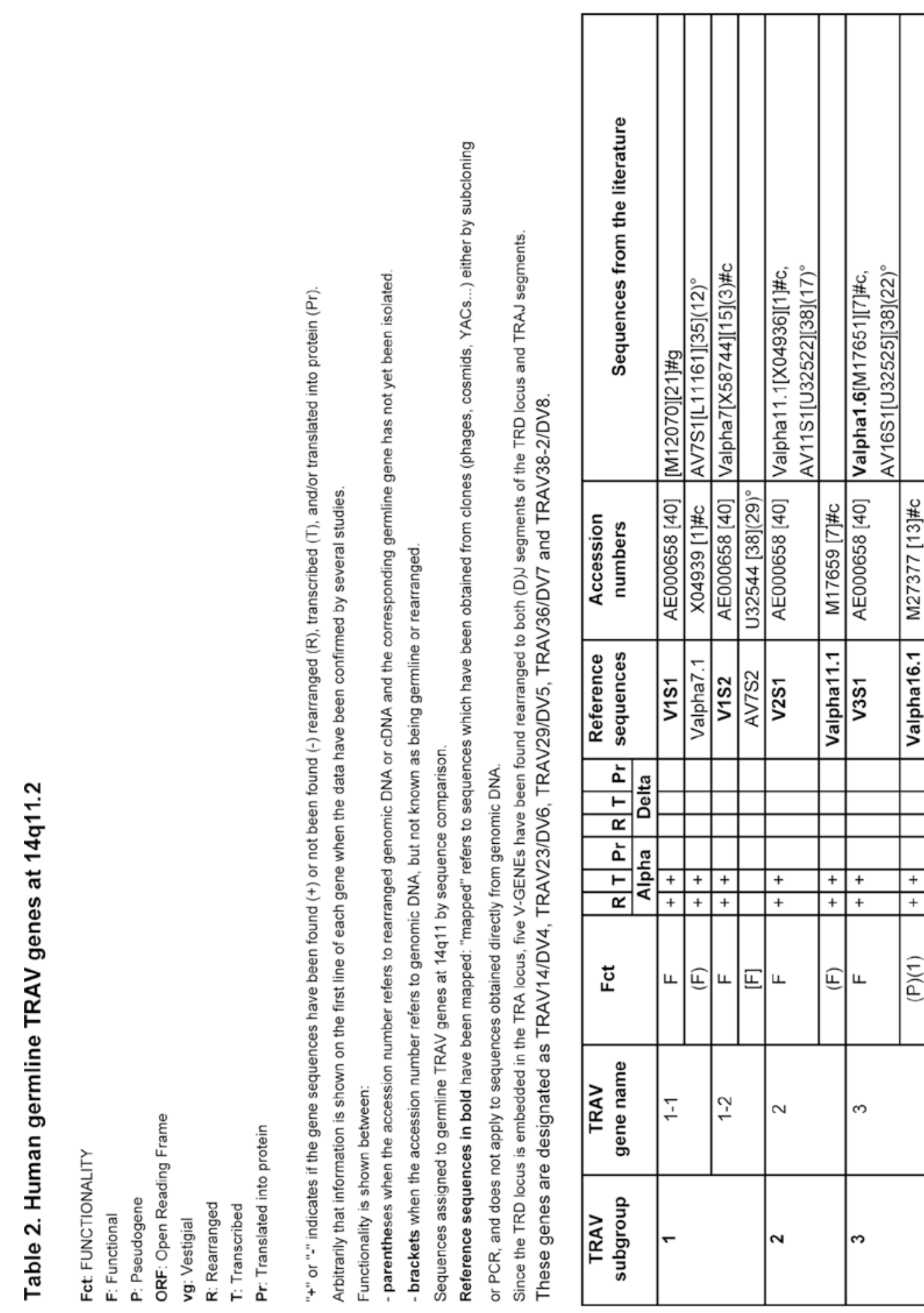

Human TRAV Genes 


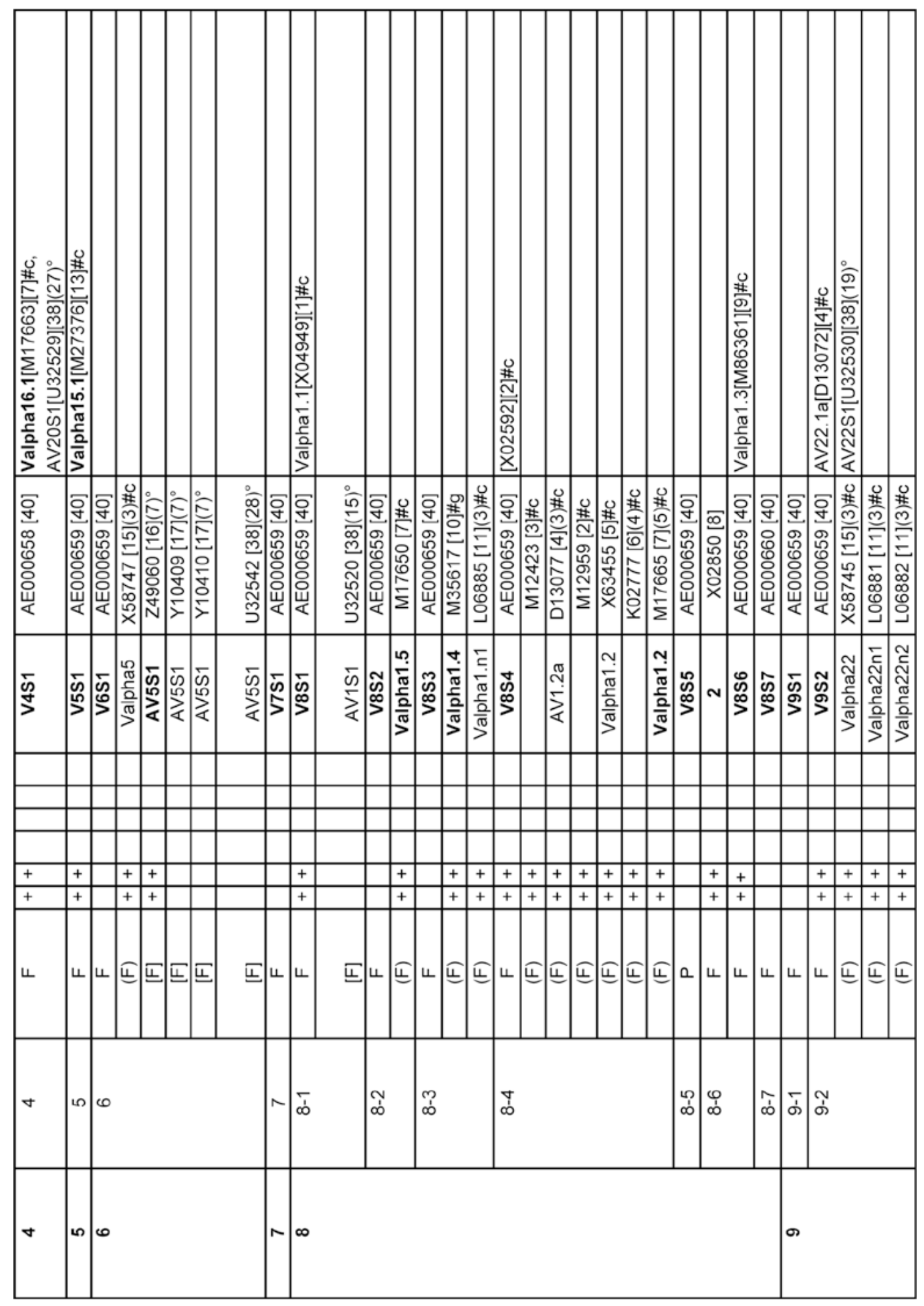




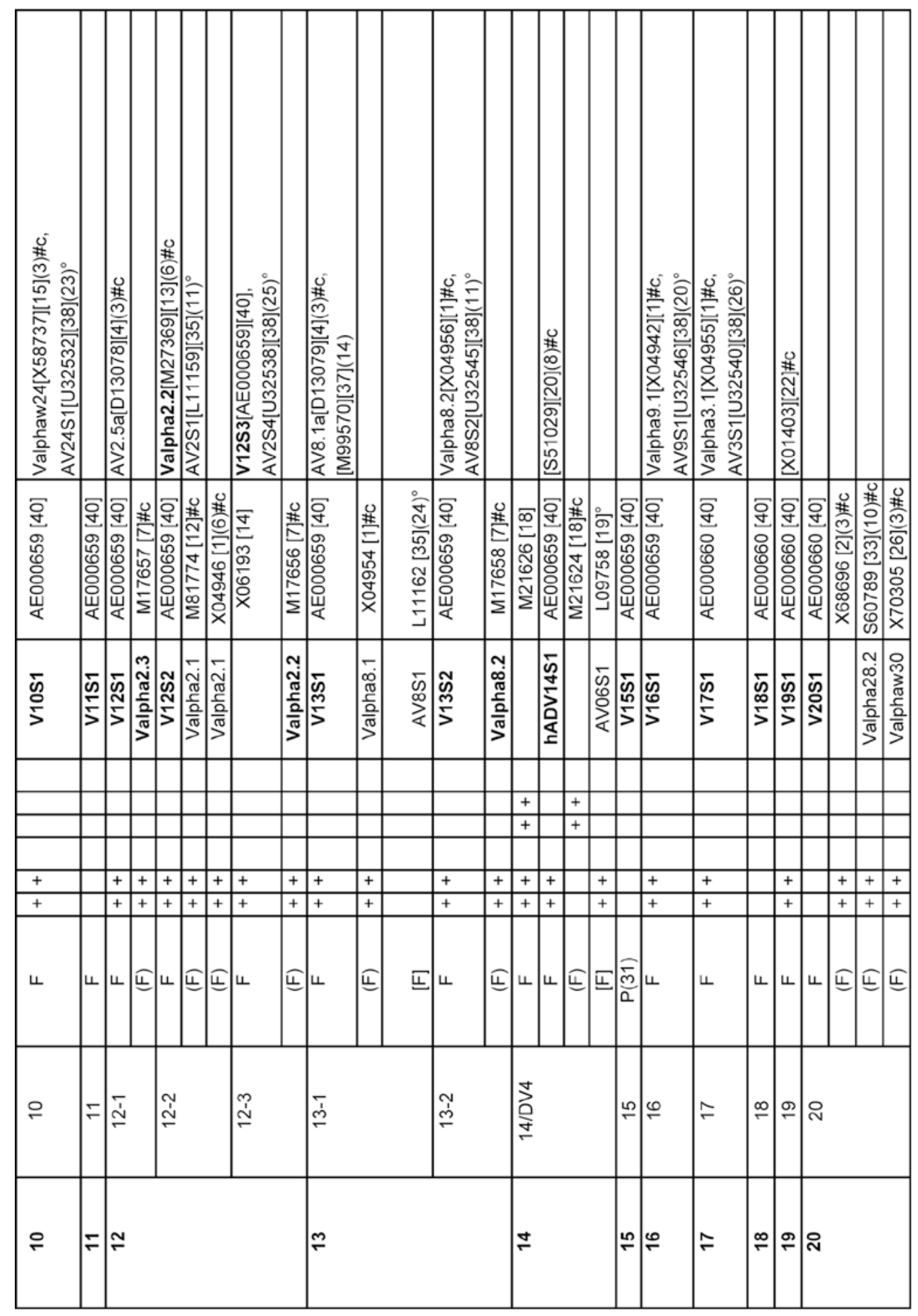

Human TRAV Genes

Exp Clin Immunogenet 2000;17:83-96 


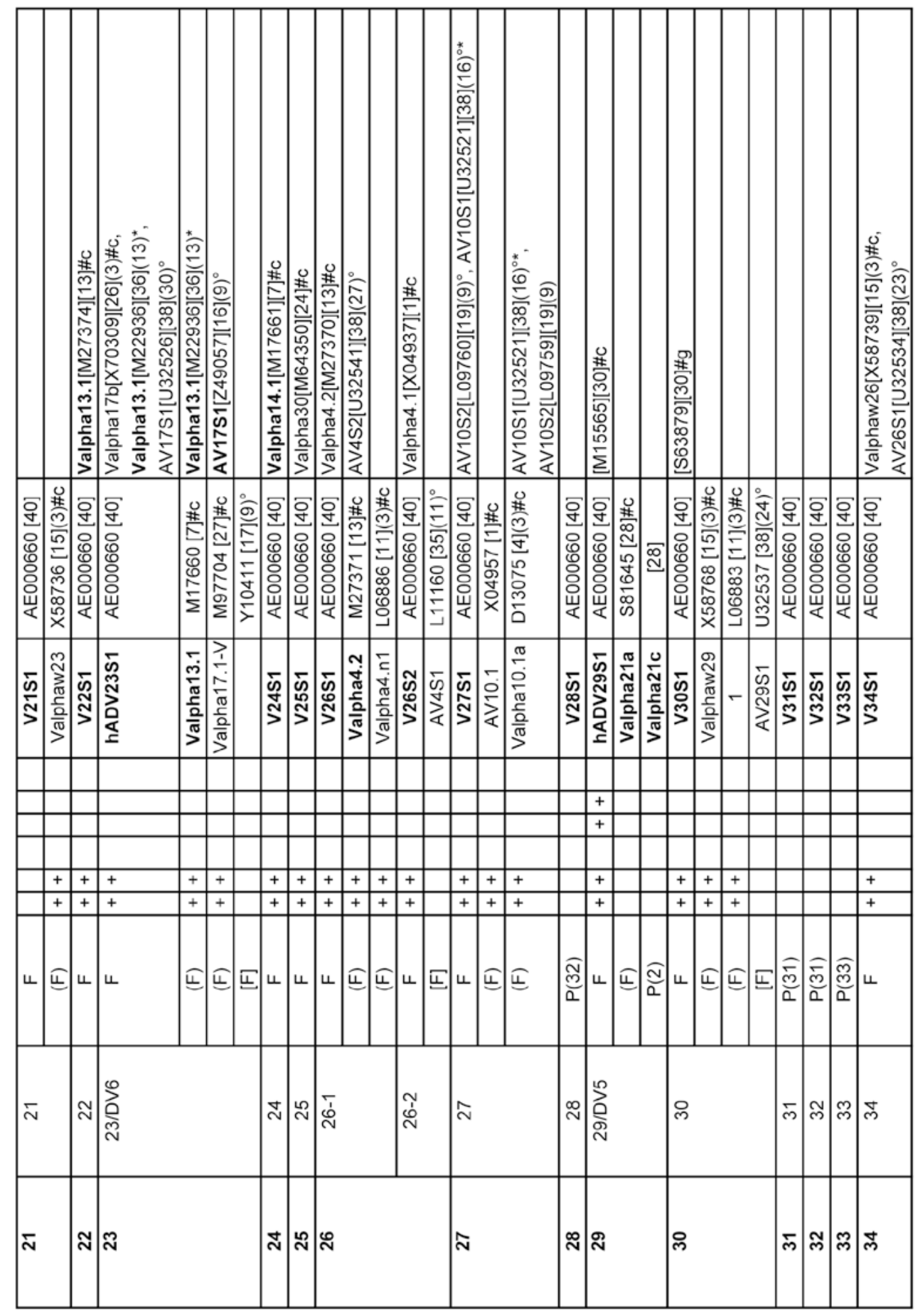




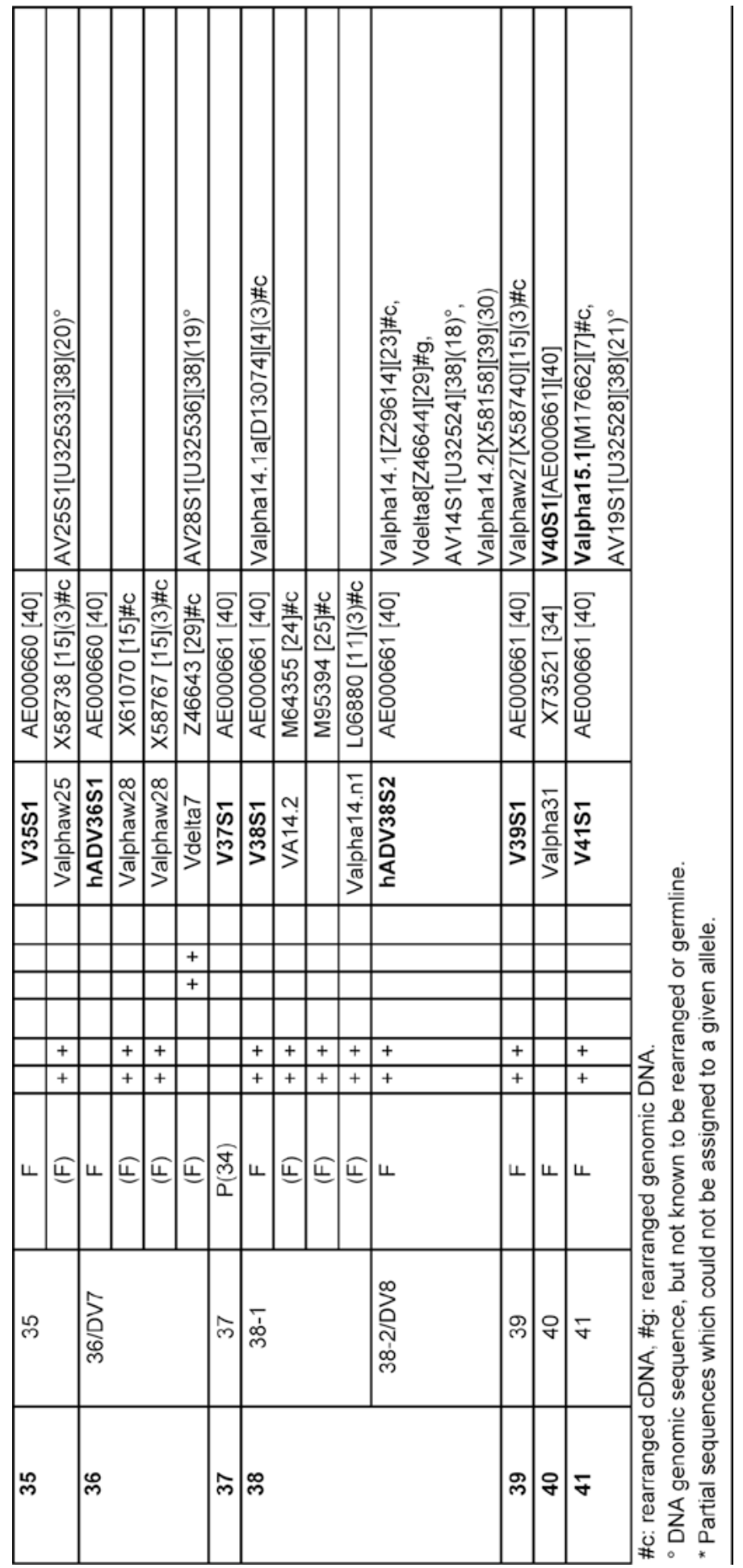

Human TRAV Genes 


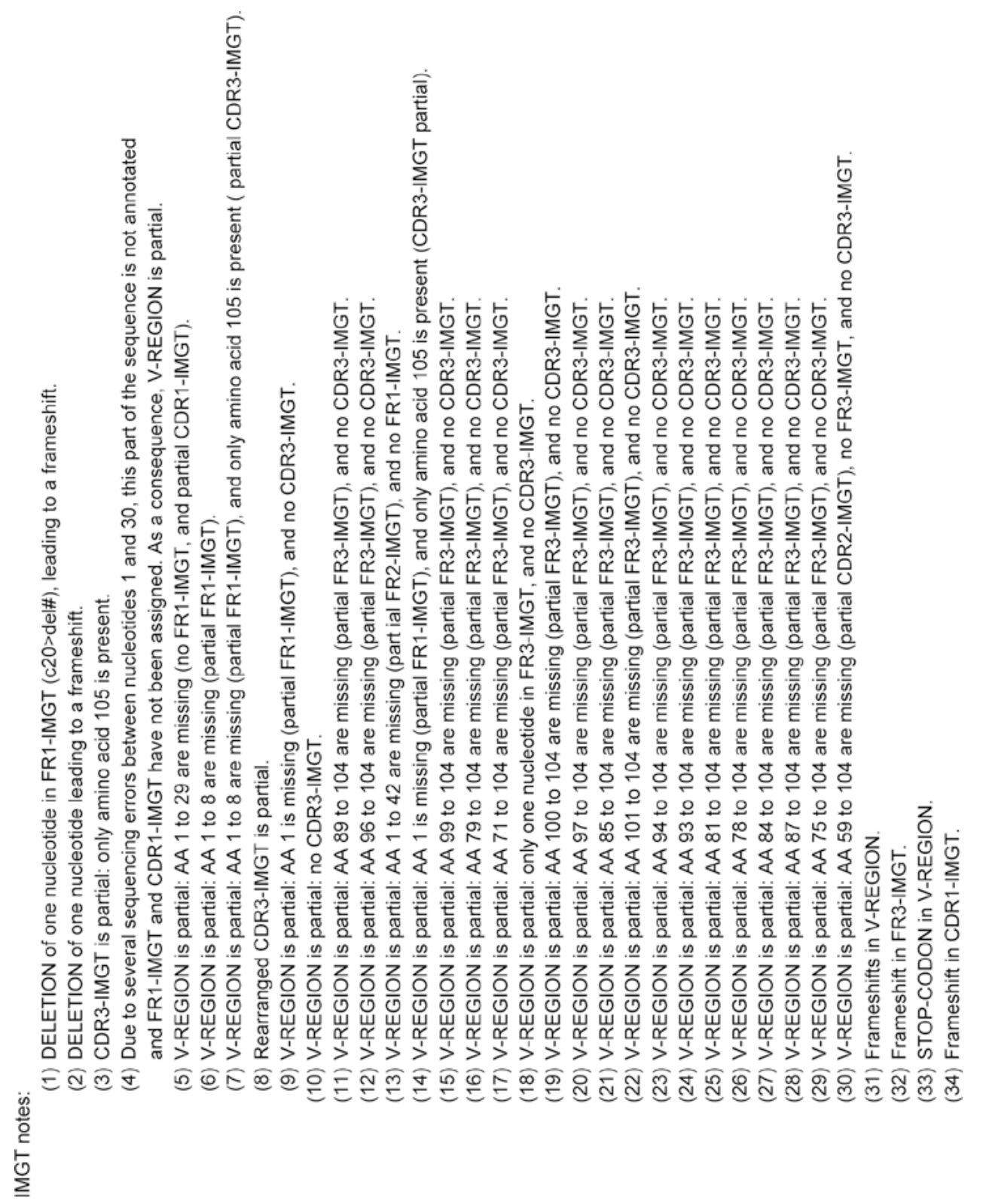

90

Exp Clin Immunogenet 2000;17:83-96

Scaviner/Lefranc 

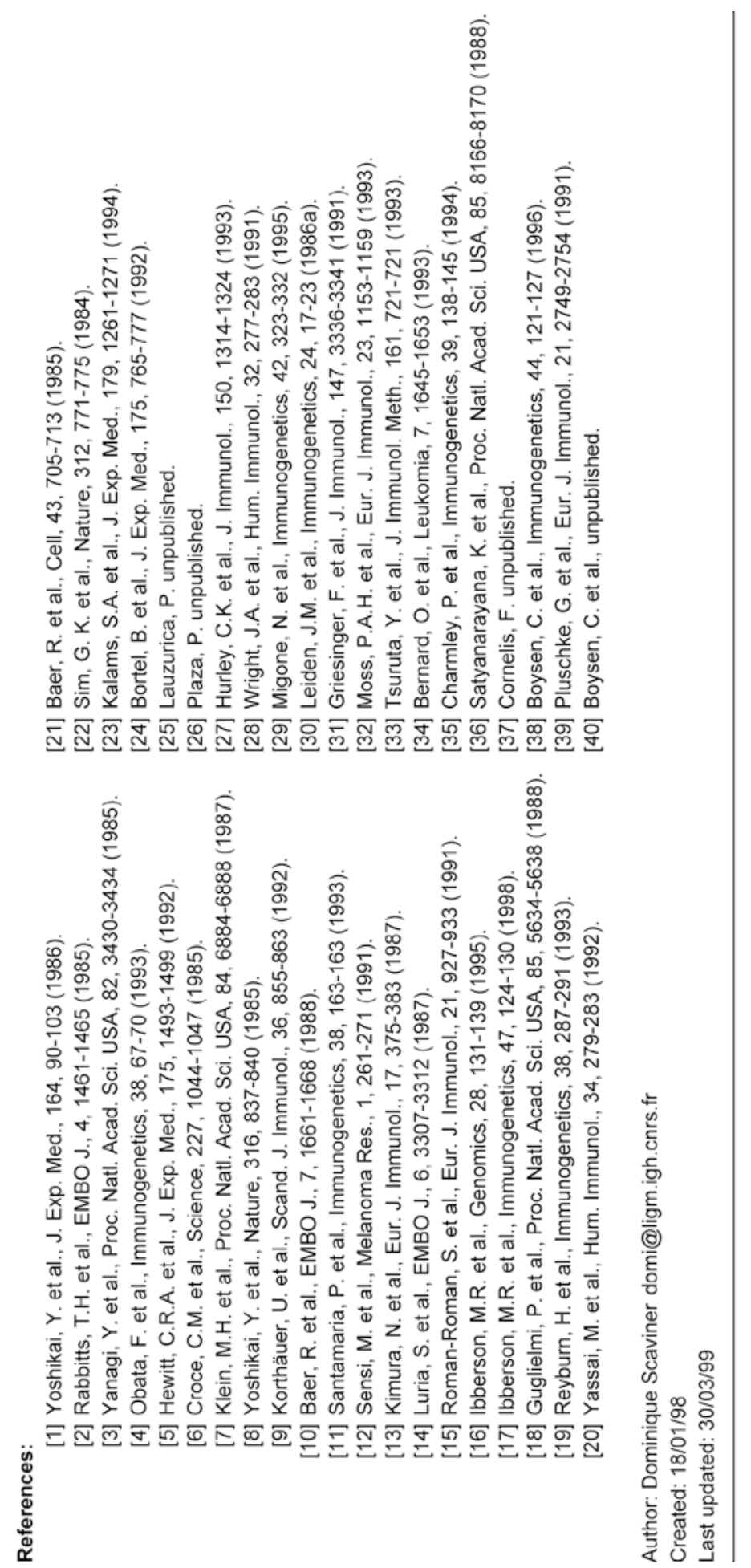

Human TRAV Genes

Exp Clin Immunogenet 2000;17:83-96 


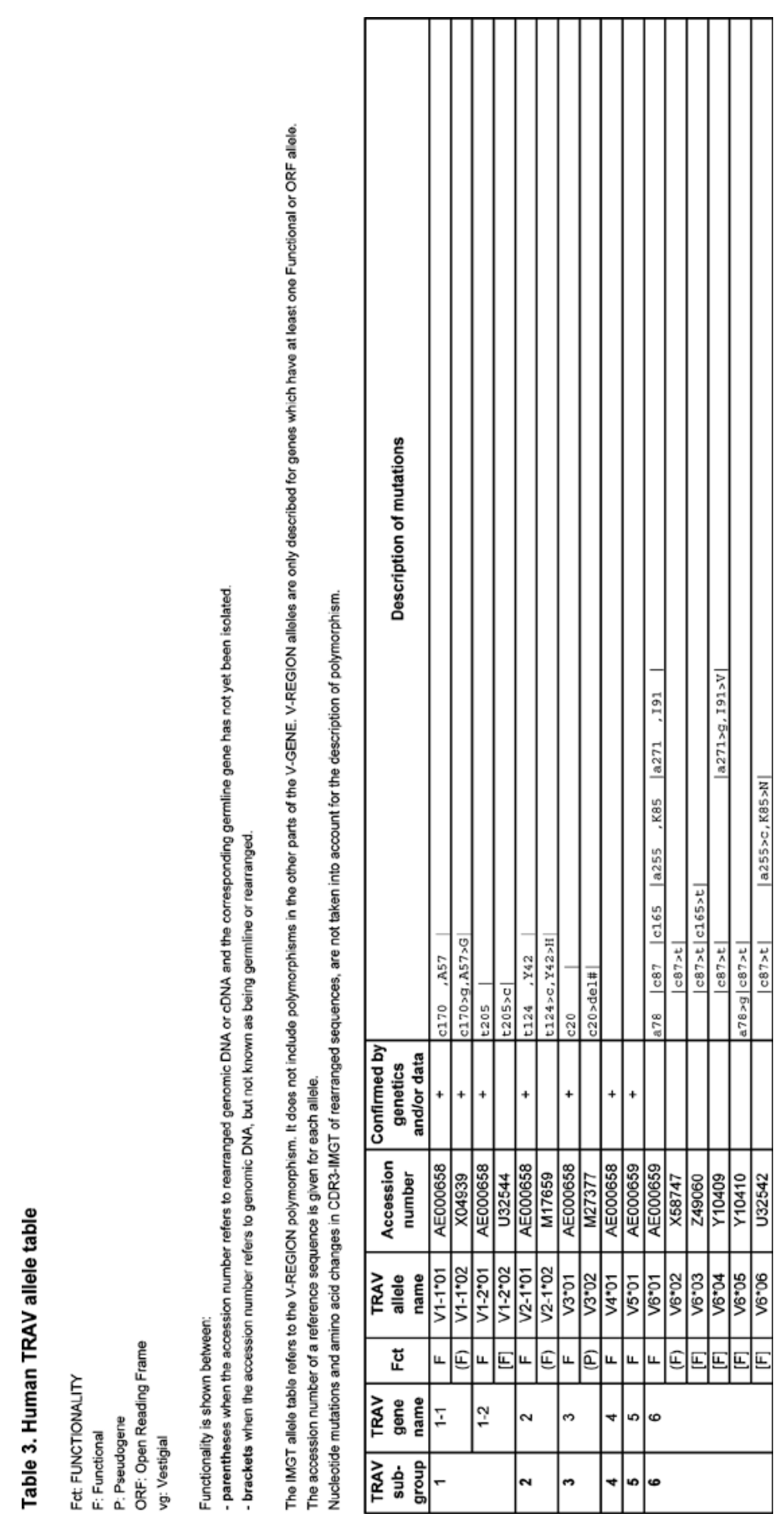

92

Exp Clin Immunogenet 2000;17:83-96

Scaviner/Lefranc 


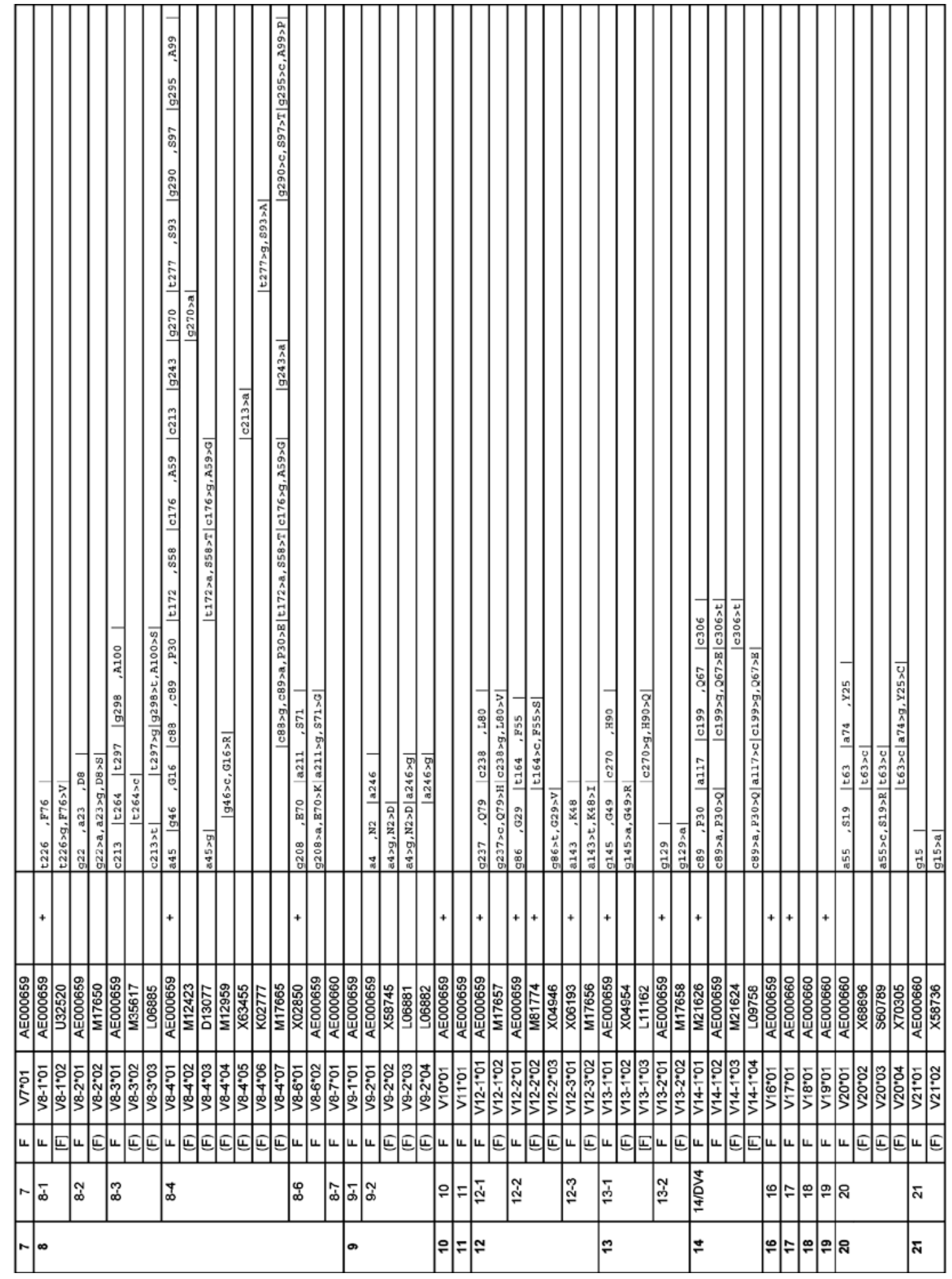

Human TRAV Genes

Exp Clin Immunogenet 2000;17:83-96 


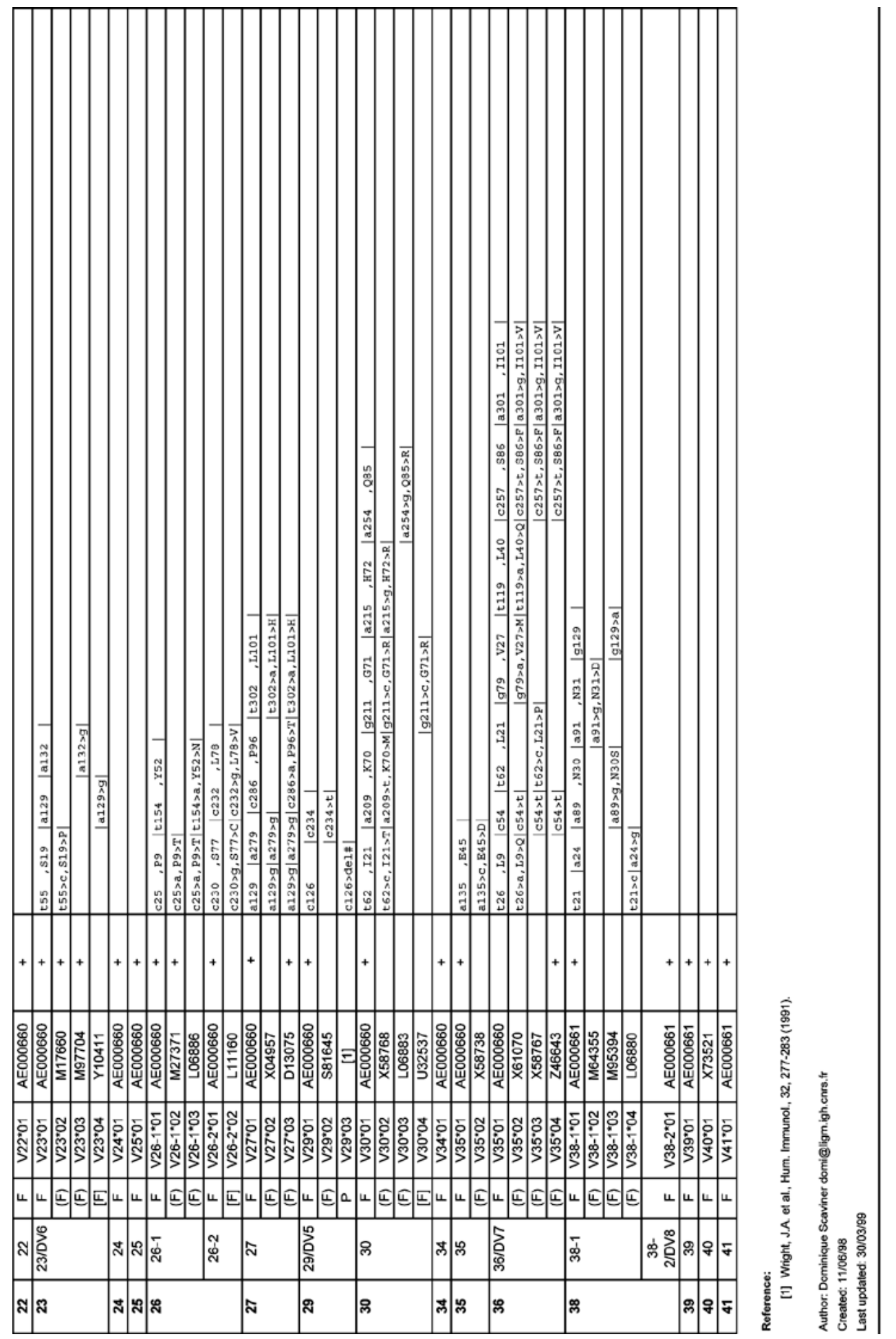

94

Exp Clin Immunogenet 2000;17:83-96

Scaviner/Lefranc 
Table 4

Correspondence between the different human TRAV gene nomenclatures

TRAV genes are listed from $3^{\prime}$ (top of the table) to $5^{\prime}$ (botom of the table)

\begin{tabular}{|c|c|c|}
\hline $\begin{array}{c}\text { IMGT } \\
\text { TRAV gene name }\end{array}$ & Boysen et al. [1] & Arden et al. [2] \\
\hline TRAV41 & $41 \mathrm{~S} 1$ & $19 \mathrm{~S} 1$ \\
\hline TRAV40 & $40 \mathrm{~S} 1$ & $31 \mathrm{~S} 1$ \\
\hline TRAV39 & $39 \mathrm{~S} 1$ & $27 \mathrm{~S} 1$ \\
\hline TRAV38-2/DV8 & hADV38S2 & 14S1-ADV14S1 \\
\hline TRAV38-1 & $38 \mathrm{~S} 1$ & $14 \mathrm{~S} 2$ \\
\hline TRAV37 & $37 \mathrm{S1}$ & \\
\hline TRAV36/DV7 & hADV36S1 & 28S1-DV28S1 \\
\hline TRAV35 & $35 \mathrm{~S} 1$ & $25 \mathrm{~S} 1$ \\
\hline TRAV34 & $34 \mathrm{~S} 1$ & $26 \mathrm{~S} 1$ \\
\hline TRAV26-2 & $26 \mathrm{~S} 2$ & $4 \mathrm{~S} 1$ \\
\hline TRAV33 & $33 \mathrm{~S} 1$ & \\
\hline TRAV32 & $32 \mathrm{~S} 1$ & \\
\hline TRAV31 & $31 \mathrm{~S} 1$ & \\
\hline TRAV30 & $30 \mathrm{~S} 1$ & $29 \mathrm{~S} 1$ \\
\hline TRAV29/DV5 & hADV29S1 & 21S1-ADV21S1 \\
\hline TRAV28 & $28 \mathrm{~S} 1$ & \\
\hline TRAV27 & $27 S 1$ & $10 \mathrm{~S} 1$ \\
\hline TRAV8-7 & $8 \mathrm{~S} 7$ & \\
\hline TRAV26-1 & $26 S 1$ & $4 \mathrm{~S} 2$ \\
\hline TRAV25 & $25 S 1$ & $32 \mathrm{~S} 1$ \\
\hline TRAV24 & $24 \mathrm{~S} 1$ & $18 \mathrm{~S} 1$ \\
\hline TRAV23/DV6 & hADV23S1 & 17S1-ADV17S1 \\
\hline TRAV22 & $22 \mathrm{~S} 1$ & $13 \mathrm{~S} 1$ \\
\hline TRAV21 & $21 S 1$ & $23 \mathrm{~S} 1$ \\
\hline TRAV20 & $20 S 1$ & $30 \mathrm{~S} 1$ \\
\hline TRAV19 & $19 \mathrm{~S} 1$ & $12 \mathrm{~S} 1$ \\
\hline TRAV18 & $18 \mathrm{~S} 1$ & \\
\hline TRAV17 & $17 \mathrm{~S} 1$ & $3 \mathrm{~S}_{1}$ \\
\hline TRAV16 & $16 \mathrm{~S} 1$ & $9 \mathrm{~S} 1$ \\
\hline TRAV8-6 & $8 \mathrm{~S} 6$ & $1 \mathrm{~S} 3$ \\
\hline TRAV12-3 & $12 \mathrm{~S} 3$ & $2 \mathrm{~S} 2$ \\
\hline TRAV15 & $15 \mathrm{~S} 1$ & \\
\hline TRAV9-2 & 9S2 & $22 \mathrm{~S} 1$ \\
\hline TRAV14/DV4 & hADV14S1 & 6S1-ADV6S1 \\
\hline TRAV13-2 & $13 \mathrm{~S} 2$ & $8 \mathrm{~S} 2$ \\
\hline TRAV8-5 & $8 \mathrm{~S} 5$ & \\
\hline TRAV8-4 & $8 S 4$ & 1S2 \\
\hline TRAV12-2 & $12 S 2$ & $2 \mathrm{~S} 1$ \\
\hline TRAV13-1 & $13 \mathrm{~S} 1$ & $8 \mathrm{~S} 1$ \\
\hline TRAV8-3 & $8 \mathrm{~S} 3$ & 154 \\
\hline TRAV8-2 & $8 \mathrm{~S} 2$ & $1 \mathrm{S5}$ \\
\hline TRAV12-1 & $12 \mathrm{~S} 1$ & $2 \mathrm{~S} 3$ \\
\hline TRAV11 & $11 \mathrm{S1}$ & \\
\hline TRAV10 & $10 \mathrm{~S} 1$ & $24 \mathrm{~S} 1$ \\
\hline TRAV9-1 & 9S1 & \\
\hline TRAV8-1 & $8 \mathrm{~S} 1$ & 1S1 \\
\hline TRAV7 & $7 \mathrm{~S} 1$ & \\
\hline TRAV6 & $6 S 1$ & $5 S 1$ \\
\hline TRAV5 & $5 S 1$ & $15 \mathrm{~S} 1$ \\
\hline TRAV4 & $4 \mathrm{~S} 1$ & $20 S 1$ \\
\hline TRAV3 & $3 \mathrm{~S} 1$ & $16 \mathrm{~S} 1$ \\
\hline TRAV2 & $2 \mathrm{S1}$ & $11 S 1$ \\
\hline TRAV1-2 & 1S2 & $7 \mathrm{~S} 2$ \\
\hline TRAV1-1 & 1S1 & $7 \mathrm{~S} 1$ \\
\hline
\end{tabular}

IMGT note:

TRAV genes are designated by a number for the subgroup [1] followed, whenever there are several genes belonging to the same subgroup, by

a dash and a number for their relative localisation in the locus.

References:

[1] Boysen, C. et al., unpublished (AEO00658-AEO00e61).

(2) Arden, B. et al., Immunogenetics, 42, 455-500 (1995).

Auther: Dominique Scaviner domichligm. igh enrs.tr

Created: 08:04:99 


\section{Acknowledgments}

We thank Valérie Contet for editorial assistance, and Véronique Giudicelli and Gérard Lefranc for helpful discussion. IMGT is funded by the European Union's BIOTECH programme (BIO4CT96-0037), Centre National de la Recherche Scientifique, and the
Ministère de l'Education Nationale, de la Recherche et de la Technologie. Subventions have been received from: Association pour la Recherche sur le Cancer, Association de la Recherche sur la Polyarthrite, Fondation pour la Recherche Médicale, Ligue Nationale contre le Cancer, and the Région Languedoc-Roussillon.

\section{References}

1 Lefranc MP: IMGT (ImMunoGeneTics) Locus on Focus. A new section of Experimental and Clinical Immunogenetics. Exp Clin Immunogenet 1998:15:1-7.

2 Pallarès N, Frippiat JP, Giudicelli V, Lefranc MP: The human immunoglobulin lambda variable (IGLV) genes and joining (IGLJ) segments. Exp Clin Immunogenet 1998;15:818.

3 Barbié V, Lefranc MP: The human immunoglobulin kappa variable (IGKV) genes and joining (IGKJ) segments. Exp Clin Immunogenet 1998;15:171-183.

4 Pallarès $\mathrm{N}$, Lefebvre $\mathrm{S}$, Contet $\mathrm{V}$, Matsuda F, Lefranc MP: The human immunoglobulin heavy variable (IGHV) genes. Exp Clin Immunogenet 1999;16:36-60.
5 Ruiz M, Pallarès N, Contet V, Barbié V, Lefranc MP: The human immunoglobulin heavy diversity (IGHD) and joining (IGHJ) segments. Exp Clin Immunogenet 1999;16:173-184.

6 Scaviner D, Barbié V, Ruiz M, Lefranc MP: Protein displays of the human immunoglobulin heavy, kappa and lambda variable and joining regions. Exp Clin Immunogenet 1999;16:234-240.

7 Folch G, Lefranc MP: The human T cell receptor beta variable (TRBV) genes. Exp Clin Immunogenet 2000;17:42-54.

8 Giudicelli V, Chaume D, Bodmer J, Müller W, Busin C, Marsh S, Bontrop R, Lemaitre M, Malik A, Lefranc MP: IMGT, the international ImMunoGeneTics database. Nucleic Acids Res 1997;25:206-211.
9 Lefranc MP, Giudicelli V, Busin C, Bodmer J, Müller W, Bontrop R, Lemaitre M, Malik A, Chaume D: IMGT, the international ImMunoGeneTics database. Nucleic Acids Res 1998;26:297-303.

10 Lefranc MP, Giudicelli V, Ginestoux C, Bodmer J, Müller W, Bontrop R, Lemaitre M, Malik A, Barbié V, Chaume D: IMGT, the international ImMunoGeneTics database. Nucleic Acids Res 1999;27: 209-212.

11 Lefranc MP: Unique database numbering system for immunogenetic analysis. Immunol Today 1997;18: 509.

12 Lefranc MP: The IMGT unique numbering for immunoglobulins, Tcell receptors, and Ig-like domains. Immunologist 1999;7:132-136. 